CLINICAL STUDY

\title{
IGF-binding protein 1 and abdominal obesity in the development of type 2 diabetes in women
}

\author{
Moira S Lewitt ${ }^{1,2}$, Agneta Hilding ${ }^{1}$, Kerstin Brismar $^{1}$, Suad Efendic ${ }^{1}$, Claes-Göran Östenson ${ }^{1}$ and Kerstin Hall ${ }^{1}$ \\ ${ }^{1}$ Department of Molecular Medicine and Surgery, Karolinska Institutet, The Rolf Luft Research Center for Diabetes and Endocrinology, Stockholm \\ SE-171 76, Sweden and ${ }^{2}$ Faculty of Science and Technology, University of the West of Scotland, Paisley Campus, Paisley PA1 2 BE, Scotland, UK \\ (Correspondence should be addressed to M S Lewitt at Faculty of Science and Technology, University of the West of Scotland; \\ Email: moira.lewitt@uws.ac.uk)
}

\begin{abstract}
Objective: Low levels of IGF-binding protein 1 (IGFBP1) are associated with metabolic syndrome and predict diabetes development in men. The aim of this study was to determine the levels of IGFBP1 in women who later develop diabetes, in relation to abdominal obesity, and to compare these levels with those of men.

Methods: IGFBP1 levels were determined at baseline and after 8 years in a case-control, prospective study of Swedish women aged 35-56 years. Individuals with normal oral glucose tolerance test (OGTT) who developed abnormal glucose regulation $(n=240)$ were pair matched to controls for age and family history of diabetes and also compared to men of the same age $(n=355)$.

Results: Low fasting IGFBP1 and increased waist measurement predicted development of diabetes in women $(n=60$; odds ratio (OR) 70, 95\% confidence interval (CI) 8-661, lowest tertile and OR 27, 95\% CI 5-141, highest tertile). In women developing diabetes, baseline IGFBP1 levels were lower than expected for fasting insulin values, were associated with impaired suppression after OGTT and increased during 8 years despite an increase in fasting insulin. All individuals in the highest tertile for waist and with $\leq 40 \%$ suppression of IGFBP1 developed diabetes within 8 years. Circulating IGFBP1 concentrations were higher in women compared to men. Women and men who developed diabetes had a similar degree of abdominal obesity, corrected for height.

Conclusions: We conclude that low IGFBP1 and elevated waist measurement predict diabetes development and that IGFBP1 production is suppressed by a novel factor(s) in women developing diabetes. Increasing levels of IGFBP1 during the emergence of diabetes in men and women suggest the emergence of hepatic insulin resistance.
\end{abstract}

European Journal of Endocrinology 163 233-242

\section{Introduction}

Insulin-like growth factor-binding protein 1 (IGFBP1) is an inhibitor of IGF actions on metabolism and growth. Circulating concentrations are determined largely by the action of insulin on its hepatic transcription (1). Low levels of IGFBP1 are associated with the metabolic syndrome and cardiovascular disease in cross-sectional studies (2-4), and predict ischaemic heart disease mortality (5). In a population study of Swedish men with normal glucose tolerance (NGT), we found that low levels of IGFBP1 predicted the development of abnormal glucose regulation 10 years later (6). During the development of diabetes however, IGFBP1 levels increased so that the regression line of IGFBP1 on insulin was above that of controls, suggesting decreased hepatic insulin sensitivity.

There are gender differences in the prevalence and consequences of diabetes. Although the prevalence is greater in men, women with diabetes are more likely to be obese $(7,8)$ and are reported to have a greater risk of cardiovascular disease $(9,10)$. Since the most effective management strategy is likely to target prevention, predictive markers may help identify women at risk. In cross-sectional studies, IGFBP1 has been identified as a marker of hyperinsulinaemia in obese postmenopausal women, both in the absence (11) and presence (12) of diabetes. The aims of this study were to compare the patterns of IGFBP1 concentrations in women with and without abnormal glucose regulation to those in men, and to determine whether IGFBP1 is also a predictive marker of abnormal glucose regulation in women. We made a novel observation that IGFBP1 concentrations are lower than expected for the insulin levels in women who later develop diabetes, suggesting a novel inhibitor of IGFBP1 production. commercial use, distribution, and reproduction in any medium, provided the original work is properly cited. 


\section{Subjects and methods}

\section{Study population}

The study population consists of participants in an epidemiological survey, the Stockholm Diabetes Prevention Programme (SDPP) (13). Individuals aged 35-56 years without known diabetes were recruited. The men were invited to participate in baseline studies earlier than the women, and were invited to follow-up studies at 10 years. The women were followed up at 8 years. Baseline and follow-up studies consisted of a questionnaire covering lifestyle factors, a health examination and an oral glucose tolerance test (OGTT). The presence of menstrual bleeding was self-reported. Blood samples were taken after an overnight fast and $2 \mathrm{~h}$ after ingestion of $75 \mathrm{~g}$ glucose.

Individuals were categorized after OGTT according to the 1999 WHO criteria (14). Diabetes was defined as a fasting plasma glucose of $\geq 7.0 \mathrm{mmol} / \mathrm{l}$ and/or 2 -h glucose of $\geq 11.1 \mathrm{mmol} / \mathrm{l}$. Impaired glucose tolerance (IGT) was defined as a 2 -h plasma glucose of $7.8-11.0 \mathrm{mmol} / \mathrm{l}$ and fasting values of $<6.1 \mathrm{mmol} / \mathrm{l}$, while impaired fasting glucose (IFG) was a fasting glucose of $6.1-6.9 \mathrm{mmol} / \mathrm{l}$ and $2-\mathrm{h}$ glucose of $<7.8 \mathrm{mmol} / \mathrm{l}$. Those with a fasting glucose of $6.1-6.9 \mathrm{mmol} / \mathrm{l}$ and $2-\mathrm{h}$ value of $7.8-11.0 \mathrm{mmol} / \mathrm{l}$ were defined as having combined glucose intolerance (IFG + IGT). The WHO classification of obesity based on body mass index (BMI) was used (15).

The population was enriched for family history of type 2 diabetes (FHD) and was at baseline present in about $50 \%$ of participants. FHD was defined as known diabetes with an onset above 35 years in at least one first-degree relative or at least two second-degree relatives.

The present study is an incident case-control study. We selected individuals with NGT at baseline who developed abnormal glucose tolerance at follow-up. In this study, men and women were the same age at the time of follow-up. Details of selection for men have been described previously (6). In women undergoing baseline assessment, a normal OGTT was found in 2397 women with and 2153 women without FHD (Fig. 1). After 8 years, 4365 women not having type 2 diabetes at baseline and still living in the same area were invited to participate in a follow-up study, and 3329 women accepted $(76 \%)$.

The study group comprised 240 women who had NGT at baseline and abnormal glucose regulation at follow-up. There were 35 women diagnosed with diabetes on OGTT at follow-up, and in 25 women, a diagnosis was made by a physician during the 8-year period. Two women in the latter group had an OGTT in the follow-up study. There were eight women taking oral hypoglycaemic agents and five women on insulin therapy. At follow-up, 119 women were diagnosed with IGT, 41 women with IFG and 20 women with IFG + IGT. The groups developing IFG and IFG+IGT were

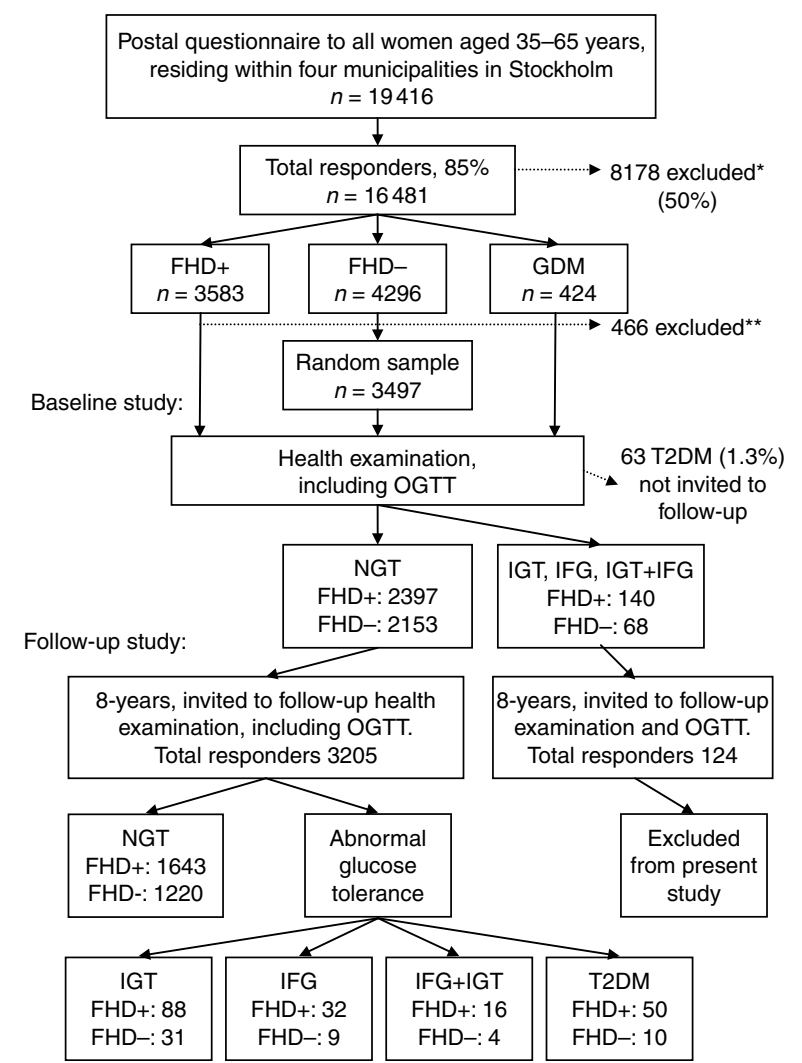

Figure 1 Study design: selection and follow-up of women in the Stockholm Diabetes Prevention Programme. The groups from which the present study population was derived were categorized according to 1999 WHO criteria and are shown in bold type. FHD+, family history of diabetes; FHD -, no family history of diabetes; GDM, history of gestational diabetes; T2DM, type 2 diabetes mellitus. *Exclusion criteria: already known diabetes (1.5\%), unclear FHD (28.5\%), insufficient FHD according to inclusion criteria $(9.9 \%)$, foreign origin $(7.6 \%)$, moved or deceased $(2.0 \%)$. ${ }^{*}$ Subjects aged 35-44 years born in the last third of each month were excluded for financial reasons.

combined for statistical analysis. The controls were pair matched to cases by random selection of 240 individuals from the group of 2863 women with NGT at baseline and at follow-up, within FHD and age. Anthropomorphic measurements were not matched in order to determine the impact of these variables. There was a history of gestational diabetes mellitus in $6.7 \%$ of cases and $2.9 \%$ of controls. As previously described (6), there were 355 men with abnormal glucose tolerance; 107 men with type 2 diabetes, 122 men with IGT, 79 men with IFG and 47 men with IFG + IGT. There were 355 male controls, pair matched from the group with NGT at baseline and at follow-up, within FHD and age.

The study was approved by the Ethics Committee of Karolinska University Hospital, and was carried out in accordance with the Declaration of Helsinki. All participants gave informed consent. 


\section{Assays}

Serum IGFBP1 was measured using an in-house RIA with intra- and inter-assay coefficient of variation $(\mathrm{CV})$ values of 3 and 10\% respectively (16). Samples from the same individual from the OGTT at baseline and at follow-up were analysed in the same assay. We have previously confirmed the stability of IGFBP1 after longterm storage (6). IGF1 was measured in serum by RIA after acid-ethanol extraction and cryoprecipitation, and using des(1-3)IGF1 (17). Intra- and inter-assay CV values were 4 and $11 \%$ respectively. Samples from the same individual were measured in the same assay.

Venous serum glucose was assayed using the glucose oxidase method (Yellow Springs Glucose Analyzer, Yellow Springs, OH, USA) and immunoreactive insulin by in-house assay, as previously described (18). Since the insulin assays were performed 8 years apart, we reanalysed baseline samples stored at $-20{ }^{\circ} \mathrm{C}$ from individuals with NGT at baseline and at follow-up. The regression line was ${ }^{10} \log (y)=0.20+0.942^{10} \log (x)$ $(n=114 ; r=0.953, P<0.001)$, where $x$ is the original measurement and $y$ is the value measured after 5-8 years in storage.

\section{Data analysis}

Results presented in the tables and figures are mean $\pm 95 \%$ CIs. We have previously described the waist ${ }^{2}$ : height ratio (waist measurement in $\mathrm{cm} / 10)^{2} /$ (height in $\left.\mathrm{m} \times 10), \mathrm{Wa}^{2} \mathrm{HtR}\right)$ in the men in this study, which we used to abolish the effect of height and allow comparisons between groups (6). The dependence of waist on height was confirmed in the women $(r=0.14$, $P=0.003$, whole group at baseline). The relationship with height was abolished when $\mathrm{Wa}^{2} \mathrm{HtR}$ was used $(r=0.01, P=0.854)$. Serum IGFBP1, IGF1 and insulin, and $\mathrm{Wa}^{2} \mathrm{HtR}$ values were log transformed before analysis. Differences between baseline and follow-up were analysed by paired Student's $t$-tests. When continuous variables were compared between two or more independent groups, unpaired t-test or ANOVA, and Scheffe's post hoc test, was used.

Linear regression analysis was used to examine the relationship between IGFBP1 and other variables. Analysis of covariance was used to investigate difference between regression lines; and also when analysing differences in IGFBP1 between groups, controlling for the effect of insulin (mean values of IGFBP1 were then computed at the mean of insulin). Forward stepwise regression analysis was performed for selection of independent predictor variables to IGFBP1.

Conditional logistic regression was performed to calculate odds ratios (ORs) and 95\% CIs. Variables were categorized in tertiles according to their distribution within the respective groups, among cases and their respective controls. The lowest tertile (for glucose, insulin, IGF1, BMI and $\mathrm{Wa}^{2} \mathrm{HtR}$ ) or the highest tertile (for IGFBP1) was used as the reference in the calculation.
Statistical analyses were performed using SAS version 9.2 (SAS Institute, Cary, NC, USA) and Statistica StatSoft version 8.0 (Tulsa, OK, USA). Statistical significance was set at $<0.01$, to take into account the repeated comparisons.

\section{Results}

\section{Control women: comparison of variables at baseline and at follow-up}

Baseline and follow-up data for the whole control group are shown in Table 1. Although the women had NGT at baseline and at follow-up, fasting and 2-h glucose values increased during the 8 -year study period. There was a $1.8 \mathrm{~kg}$ gain in weight, and waist measurement increased by $5 \mathrm{~cm}$. When waist was corrected for height ( $\mathrm{Wa}^{2} \mathrm{HtR}$ ), there was a $12 \%$ increase over the 8 -year study period $(95 \%$ CI $10-14, P<0.001)$. There was a fall in IGF1 concentrations.

Fasting and 2-h insulin concentrations increased at follow-up, compared to baseline; and fasting (f)-IGFBP1 level declined significantly. There was an inverse relationship between f-IGFBP1 and f-insulin both at baseline $(r=-0.40, P<0.001)$ and at followup $(r=-0.44, P<0.001)$. There were also inverse relationships between f-IGFBP1 and IGF1 $(r=-0.38$, $P<0.001$ at baseline and $r=-0.32, \quad P<0.001$ at follow-up) and between f-IGFBP1 and $\mathrm{Wa}^{2} \mathrm{HtR}$ $(r=-0.35, P<0.001$ at baseline and $r=-0.38$, $P<0.001$ at follow-up). In multiple regression analysis, $31 \%$ of the f-IGFBP1 variation at baseline could be accounted for by these three variables $(P<0.001)$.

\section{Women developing abnormal glucose regulation: variables at baseline}

Baseline data for the women having type 2 diabetes at follow-up are shown in Table 2, and those developing IFG/IFG + IGT or IGT are shown in Supplementary Tables 1 and 2, see section on supplementary data given at the end of this article respectively. Women who developed diabetes weighed more than controls matched for FHD and age, and had higher BMI values and elevated $\mathrm{Wa}^{2} \mathrm{HtR}$. They had fasting and 2-h IGFBP1 levels that were lower, and fasting and 2-h insulin values that were higher at baseline compared to controls. Furthermore, the regression line of f-IGFBP1 on f-insulin was significantly below that of the matched control group (Fig. 2a), so that the levels of IGFBP1 in relation to insulin were on average $70 \%$ of the levels in controls $(P<0.001)$. At baseline, $26 \%$ of the f-IGFBP1 variation in the diabetes group at baseline could be accounted for by the variable $\mathrm{Wa}^{2} \mathrm{HtR}(P<0.001)$ and, in multiple regression analysis, this was increased to $31 \%$ by the addition of IGF1 $(P=0.024)$ and to $34 \%$ with insulin $(P=0.080)$. Notably, IGFBP1 was less suppressed following $75 \mathrm{~g}$ oral glucose compared with 
Table 1 Data for all control subjects: women at baseline, and men and women at follow-up.

\begin{tabular}{|c|c|c|c|c|c|}
\hline \multirow[b]{3}{*}{ Variables } & \multicolumn{3}{|c|}{ Women $(n=240)$} & \multirow{2}{*}{\multicolumn{2}{|c|}{$\frac{\text { Men }(n=355)}{\text { Follow-up }^{\mathrm{a}}}$}} \\
\hline & \multirow{2}{*}{$\begin{array}{c}\text { Baseline } \\
\text { Mean }(95 \% \mathrm{Cl})\end{array}$} & \multicolumn{2}{|c|}{ Follow-up ${ }^{a}$} & & \\
\hline & & Mean $(95 \% \mathrm{Cl})$ & $P$ value ${ }^{b}$ & Mean $(95 \% \mathrm{Cl})$ & $P$ value \\
\hline Age (years) & $49.1(48.6-49.7)$ & $57.3(56.8-57.9)$ & $<0.001$ & $57.7(57.2-58.2)$ & 0.360 \\
\hline Height $(m)$ & $1.67(1.66-1.67)$ & $1.66(1.65-1.66)$ & $<0.001$ & $1.79(1.78-1.79)$ & $<0.001$ \\
\hline Weight (kg) & $68.5(67.2-69.8)$ & $70.3(68.9-71.7)$ & $<0.001$ & $85.9(84.7-87.2)$ & $<0.001$ \\
\hline $\operatorname{BMI}\left(\mathrm{kg} / \mathrm{m}^{2}\right)$ & $24.7(24.2-25.1)$ & $25.6(25.1-26.1)$ & $<0.001$ & $26.9(26.5-27.2)$ & $<0.001$ \\
\hline Waist $(\mathrm{cm})$ & $79(78-80)$ & $84(82-85)$ & $<0.001$ & $94(93-953)$ & $<0.001$ \\
\hline Hip (cm) & $100(99-101)$ & $99(98-100)$ & 0.132 & $102(102-103)$ & $<0.001$ \\
\hline Waist/hip & $0.79(0.79-0.80)$ & $0.84(0.84-0.85)$ & $<0.001$ & $0.92(0.92-0.93)$ & $<0.001$ \\
\hline $\mathrm{Wa}^{2} \mathrm{HtR}^{\mathrm{d}}$ & $3.71(3.61-3.81)$ & $4.17(4.05-4.29)$ & $<0.001$ & $4.94(4.85-5.03)$ & $<0.001$ \\
\hline IGF1 $\left(\mu \mathrm{g} / \mathrm{I}^{\mathrm{d}}\right.$ & $170(164-177)$ & $153(147-159)$ & $<0.001$ & $165(160-170)$ & 0.003 \\
\hline Systolic BP (mmHg) & $120(118-122)$ & $133(131-135)$ & $<0.001$ & 135 (133-136) & 0.304 \\
\hline Diastolic BP (mmHg) & $74(73-76)$ & $82(81-83)$ & $<0.001$ & $83(82-84)$ & 0.424 \\
\hline \multicolumn{6}{|l|}{ Glucose $(\mathrm{mmol} / \mathrm{l})$} \\
\hline $\mathrm{Oh}$ & $4.7(4.6-4.7)$ & $4.9(4.8-4.9)$ & $<0.001$ & $5.0(5.0-5.1)$ & $<0.001$ \\
\hline $2 \mathrm{~h}$ & $4.5(4.4-4.7)$ & $4.8(4.7-4.9)$ & $<0.001$ & $5.0(4.9-5.2)$ & 0.019 \\
\hline \multicolumn{6}{|l|}{ Insulin $(\mathrm{pmol} / /)^{\mathrm{d}}$} \\
\hline $\mathrm{Oh}$ & $60(57-63)$ & $83(79-87)$ & $<0.001$ & $89(85-93)$ & 0.035 \\
\hline $2 \mathrm{~h}$ & $198(186-211)$ & $273(256-291)$ & $<0.001$ & 277 (261-295) & 0.702 \\
\hline \multicolumn{6}{|l|}{ IGFBP1 $\left(\mu \mathrm{g} / \mathrm{I}^{\mathrm{d}}\right.$} \\
\hline $\mathrm{Oh}$ & $41(39-44)$ & $38(36-41)$ & 0.009 & $19(18-20)$ & $<0.001$ \\
\hline $2 \mathrm{~h}$ & $20(19-22)$ & $19(18-21)$ & 0.040 & $10(9-10)$ & $<0.001$ \\
\hline 2 h/0 h (\%) & $49(48-51)$ & $50(49-52)$ & 0.415 & $50(48-52)$ & 0.882 \\
\hline Obesity frequency & $8 \%$ & $12 \%$ & & $18 \%$ & \\
\hline FHD frequency & $70 \%$ & $78 \%$ & & $69 \%$ & \\
\hline Menstruating $^{f^{\dagger}}$ & $67 \%$ & $12 \%$ & & & \\
\hline
\end{tabular}

${ }^{\text {a}}$ Follow-up 8 years for women and 10 years for men.

${ }^{\mathrm{b}}$ Paired $t$-test.

'Unpaired $t$-test, men versus women.

${ }^{\mathrm{d}}$ Geometric mean.

${ }^{e}$ According to WHO criteria (BMI $\left.\geq 30\right)$.

fSelf-reported regular or irregular bleeding.

the matched controls (Table 2 and Fig. 2c), and the suppression of IGFBP1 was related to the f-IGFBP1 levels (Fig. 3a).

Women developing IGT or IFG/IFG + IGT had f-IGFBP1 and 2-h IGFBP1 levels at baseline that were lower than pair-matched controls (IGT: f-IGFBP1 $30 \mu \mathrm{g} / \mathrm{l}, \quad 95 \%$ CI 27-33, P<0.001; 2-h IGFBP1 $16 \mu \mathrm{g} / \mathrm{l}, 95 \% \mathrm{CI} 14-17, P<0.001$ and IFG/IFG + IGT: f-IGFBP1 $27 \mu \mathrm{g} / \mathrm{l}, \quad 95 \%$ CI 24-31, $\quad \mathrm{P}<0.001 ; 2-\mathrm{h}$ IGFBP1 $14 \mu \mathrm{g} / \mathrm{l}, 95 \% \mathrm{CI} 13-16, P<0.001)$ and similar to the values seen in women developing diabetes mellitus $(P=0.095$, one-way ANOVA). Unlike the women developing diabetes, however, those who were to develop IGT or IFG/IFG + IGT had IGFBP1 levels that were similarly suppressed in response to glucose challenge, compared with controls $(52 \%, 95 \%$ CI $50-54 \%$ and $52 \%, 95 \%$ CI $48-56 \%$ for IGT and IFG/IFG + IGT respectively).

\section{Factors predicting the development of abnormal glucose regulation in women}

Baseline variables were categorized into tertiles, and ORs for the development of IGT, IFG or IFG + IGT and diabetes were determined (Fig. 4 and Supplementary Tables 3-5, see section on supplementary data given at the end of this article). Individuals in the lowest tertile for IGFBP1 at baseline had a 70-fold increased risk of diabetes, and a 3- and 13-fold increased risk of IGT and IFG/IFG + IGT respectively. Similar ORs were seen for those in the highest tertiles for $\mathrm{Wa}^{2} \mathrm{HtR}$.

When f-IGFBP1 was log transformed and used as a continuous variable, the OR for the risk of diabetes was 5.69 (95\% CI 2.37-13.65, $P<0.001)$ for each $50 \%$ decrease in f-IGFBP1. Increasing values of $\mathrm{Wa}^{2} \mathrm{HtR}$ were also associated with the risk of diabetes $(P<0.001)$. When combined in a conditional logistic regression analysis, $W \mathrm{a}^{2} \mathrm{HtR}$ remained independently associated $(P=0.009)$, while $\mathrm{f}-\mathrm{IGFBP} 1^{-1}$ was excluded $(P=0.034)$.

\section{Women developing abnormal glucose regulation: variables at follow-up}

Diabetes After the development of diabetes, f-IGFBP1 levels had increased by $22 \%$ (95\% CI 6-41) in contrast to a fall in the matched control group $(-11 \%, 95 \% \mathrm{CI}$ $-22-1 ; P=0.001$, cases versus controls). The increase in f-IGFBP1 was observed despite increases in insulin values that were not significantly different to the matched controls $(61 \%, 95 \%$ CI $43-81$ vs $38 \%$, 95\% 


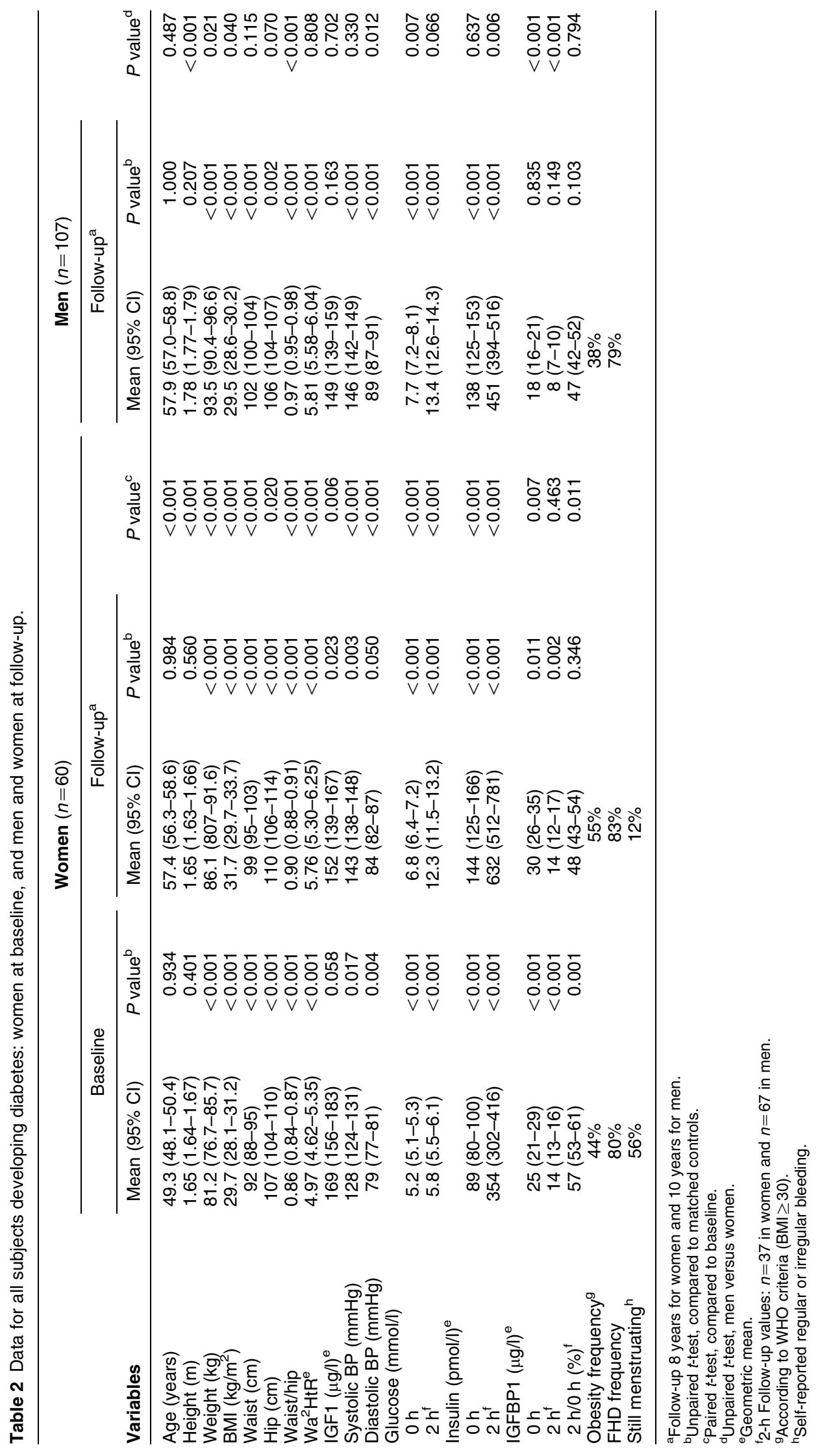



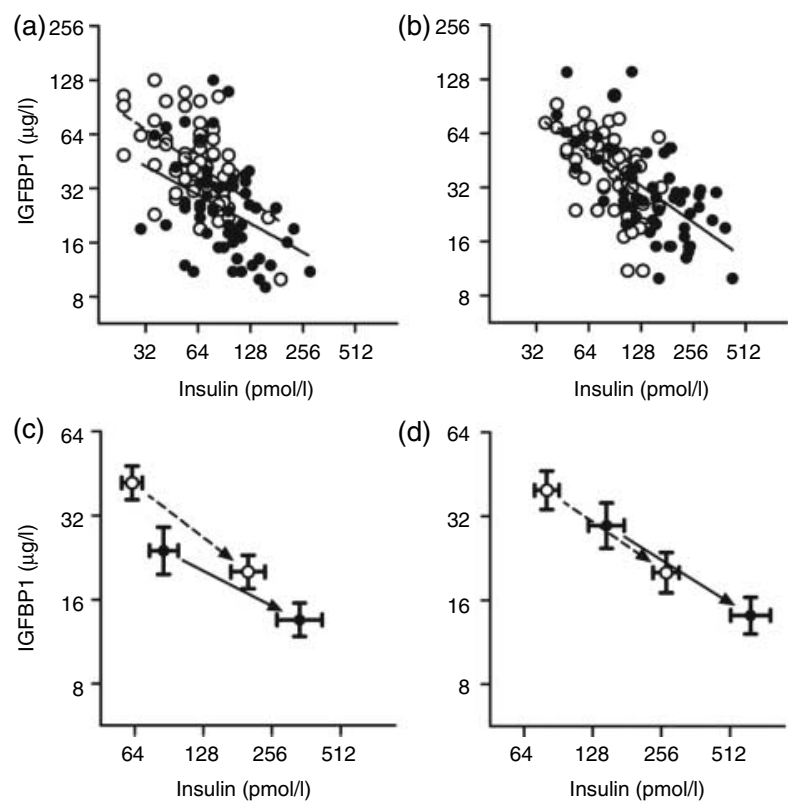

Figure 2 Relationship between IGFBP1 and insulin concentrations in women developing type 2 diabetes at baseline (a and c) and at 8-year follow-up (b and d). The relationship between fasting values is shown in (a) and (b) $(n=60)$, while the fasting and 2-h response (means and $95 \% \mathrm{Cl}$ ) to a $75 \mathrm{~g}$ OGTT are shown for the 37 individuals undergoing this test both at baseline (c) and at follow-up (d). The individuals developing diabetes are represented by the solid circles and unbroken regression lines, and are compared to their matched controls, which are represented by the open circles and broken regression lines. Regression lines and correlation coefficients: (a) controls:

${ }^{2} \log ($ IGFBP1 $)=9.394-\left(0.661 \times{ }^{2} \log (\right.$ insulin $\left.)\right), r=-0.55, P<0.001$; diabetes: ${ }^{2} \log ($ IGFBP1 $)=8.065-\left(0.531 \times{ }^{2} \log\right.$ (insulin)), $r=-0.40$, $P=0.002$; (b) controls: ${ }^{2} \log ($ IGFBP1 $)=10.020-\left(0.738 \times{ }^{2} \log\right.$ (insulin)), $r=-0.53, P<0.001$; diabetes: ${ }^{2} \log ($ IGFBP1 $)=9.766-$ $\left(0.677 \times{ }^{2} \log (\right.$ insulin) $), r=-0.64, P<0.001$.

CI 24-55, $P=0.065$, unpaired $t$-test). The regression line of f-IGFBP1 on f-insulin shifted upwards to meet the line for matched controls (Fig. 2b), and women with diabetes at follow-up had on average $64 \%$ higher f-IGFBP1 in relation to insulin, compared to baseline levels $(P<0.001)$. In the control group, the decrease in IGFBP1 was related to the increase in insulin concentrations with time (Fig. 5a), while in the diabetes group, this relationship between the change in f-IGFBP1 and f-insulin was not observed. The change in IGFBP1 was inversely correlated to the change in IGF1 in the group developing diabetes but not in the controls (Fig. 5b). At follow-up, the ability of a glucose challenge to suppress IGFBP1 was not different to controls (Table 2 and Fig. 2d).

There was a tendency to a greater weight increase in the women developing diabetes compared to matched controls ( $5.0 \mathrm{~kg}, 95 \%$ CI $2.8-7.3$ vs $1.9 \mathrm{~kg}$, 95\% CI $0.3-$ $3.4, P=0.022)$, and there was a greater increase in the Wa ${ }^{2} \mathrm{HtR}(0.86,95 \%$ CI $0.63-1.09$ vs 0.47 , 95\% CI $0.28-0.65, P=0.009)$. The increase in $W^{2} \mathrm{HtR}$ and the $\mathrm{Wa}^{2} \mathrm{HtR}$ value at baseline were associated with less suppression of IGFBP1 after an oral glucose load at
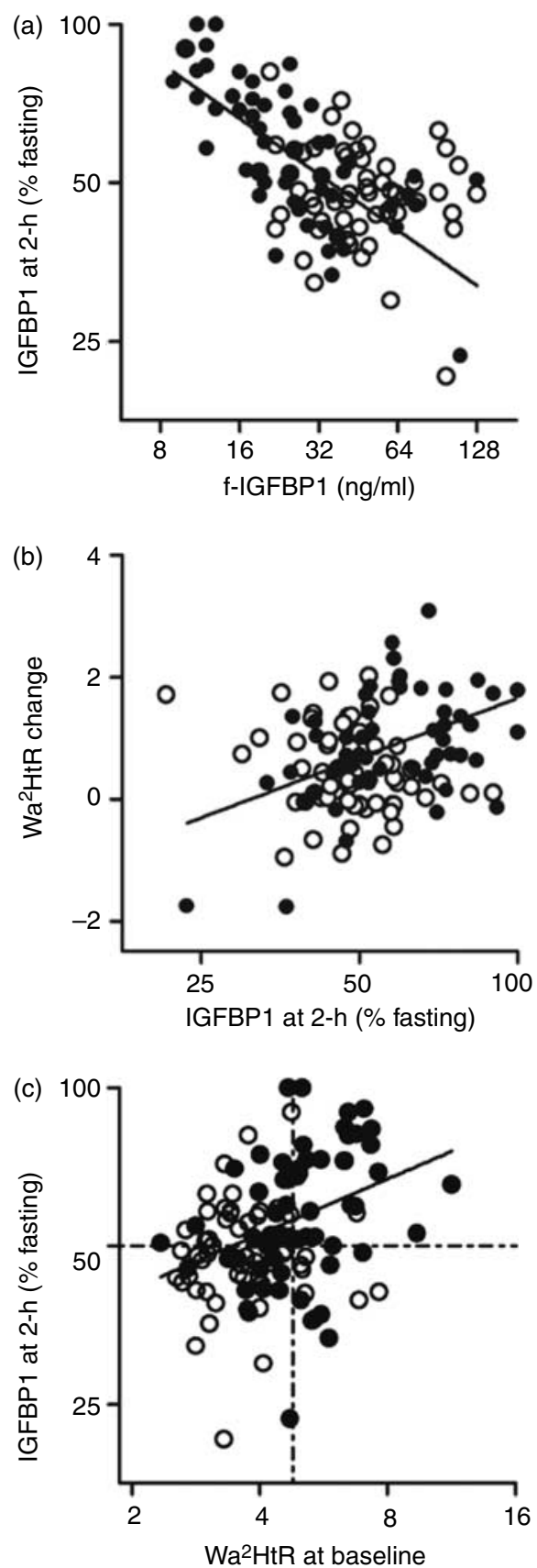

Figure 3 Relationship between the suppression of IGFBP1 by oral glucose and the fasting (f)-IGFBP1 levels and Wa ${ }^{2} \mathrm{HtR}$. The suppression of IGFBP1 at $2 \mathrm{~h}$ at baseline, expressed as a percentage of the fasting values, is related to the fasting (f)-IGFBP1 in women at baseline, 8 years before the development of diabetes (a), to the increase in waist measurement $\left(\mathrm{Wa}^{2} \mathrm{HtR}\right)$ over 8 years $(\mathrm{b})$ and to the baseline $\mathrm{Wa}^{2} \mathrm{HtR}$ (c). The individuals developing diabetes $(n=60)$ are represented by the solid circles and unbroken regression lines, and are compared to their matched controls, which are represented by the open circles. The vertical line represents the cut-off value of the highest tertile for $\mathrm{Wa}^{2} \mathrm{HtR}$ (c). Correlation coefficients: (a) controls: $r=-0.30, P=0.018$; diabetes: $r=-0.71, P<0.001$; (b) controls: $r=-0.23, P=0.074$; diabetes: $r=0.47, P<0.001$; (c) controls: $r=0.05$,

$P=0.702$; diabetes: $r=0.34, P=0.008$. 
baseline in the group with diabetes (Fig. 3b and c). All of the individuals in the highest tertile for $\mathrm{Wa}^{2} \mathrm{HtR}$ and with $\leq 40 \%$ suppression of IGFBP1 developed diabetes within 8 years $(n=19)$, and all but one individual in the highest tertile had $\leq 50 \%$ suppression $(n=26)$.

IFG and/or IGT Fasting IGFBP1 did not change over the 8 years in any of these groups (IGT: $29 \mu \mathrm{g} / \mathrm{l}, 95 \% \mathrm{CI}$ 26-32, $P=0.358$ compared to baseline and IFG or IFG+IGT: $25 \mu \mathrm{g} / \mathrm{l}, 22-28, P=0.135$; Supplementary Tables 1 and 2), while the 2-h IGFBP1 fell in those with IFG or IFG + IGT (IGT: $14 \mu \mathrm{g} / \mathrm{l}, 95 \%$ CI 13-15, P=0.022 compared with baseline and IFG or IFG + IGT: $12 \mu \mathrm{g} / \mathrm{l}$, 11-13, $P<0.004)$. Fasting and $2-\mathrm{h}$ values remained lower at follow-up compared to matched controls in all groups $(P<0.001)$.

\section{Gender differences}

We have previously reported the baseline variables for men in SDPP trial who developed abnormal glucose regulation (6). Here, we present the follow-up data for the men with diabetes in order to compare them with women of the same age. Women with NGT at baseline and at follow-up had lower values of waist and weight measurements compared with men (Table 1). Control women, however, had a greater increase in $\mathrm{Wa}^{2} \mathrm{HtR}$ over an 8-year period $(12 \%, 95 \%$ CI 10-14) compared with control men of similar age over the preceding 10 years (6\%, 95\% CI 4-8, P<0.001, unpaired $t$-test). Women and men who developed diabetes in the preceding 8 or 10 years had waist measurements that were not different at follow-up (Table 2). In these women, the $\mathrm{Wa}^{2} \mathrm{HtR}$ measurement was $38 \%$ higher than their controls, while men had measurements that were $20 \%$ higher than their control group. More women developing diabetes met the WHO definition of obesity (BMI $\geq 30)$ compared with men at baseline and at follow-up.

Women had higher f-IGFBP1 and 2-h IGFBP1 levels than men, in individuals with NGT (Table 1), in those developing type 2 diabetes (Table 2), in IGT (f-IGFBP1 $29 \mu \mathrm{g} / \mathrm{l}, 95 \%$ CI $26-32$ vs $16 \mu \mathrm{g} / \mathrm{l}, 95 \%$ CI $14-18$ for women and men respectively at follow-up, $P<0.001$; 2-h IGFBP1 $14 \mu \mathrm{g} / \mathrm{l}, 95 \%$ CI 13-15 vs $8 \mu \mathrm{g} / \mathrm{l}, 95 \%$ CI $7-9, \quad P<0.001$ ) and in IFG or IFG + IGT (f-IGFBP1 $25 \mu \mathrm{g} / \mathrm{l}, 95 \%$ CI $22-28$ vs $14 \mu \mathrm{g} / \mathrm{l}, 95 \%$ CI $13-16$ for women and men respectively at follow-up, $P<0.001$; 2-h IGFBP1 $12 \mu \mathrm{g} / \mathrm{l}, 11-13$ vs $7 \mu \mathrm{g} / \mathrm{l}, 95 \%$ CI $6-8$, $P<0.001)$. The higher f-IGFBP1 levels were seen despite similar f-insulin values compared with men.

\section{Discussion}

In this population-based prospective study of women, low fasting IGFBP1 concentrations predicted the development of abnormal glucose regulation 8 years later. Women who later developed diabetes had levels of fasting IGFBP1 that were lower than expected for the fasting insulin values, and were associated with
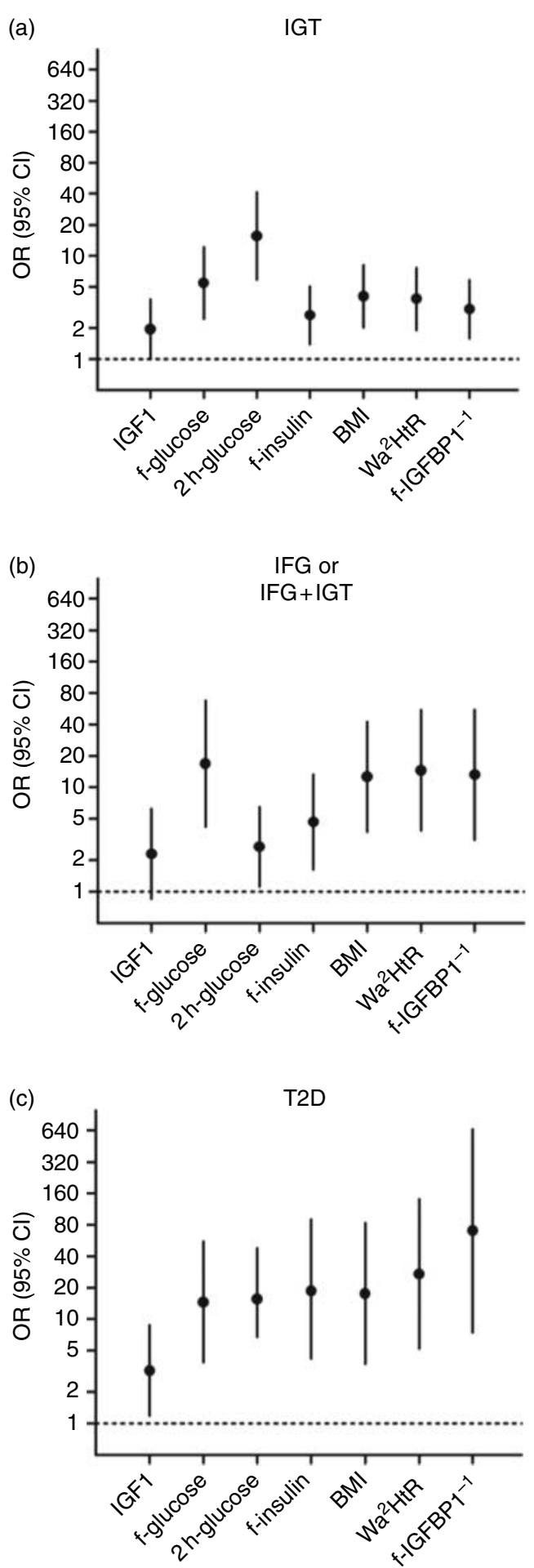

Figure 4 ORs (95\% Cls) of variables for the development of IGT (a), IFG or IFG + IGT (b) and type 2 diabetes (c) in women. The lowest tertile was used as the reference in the calculation. Note that the inverse of IGFBP1 was used. f, fasting. 

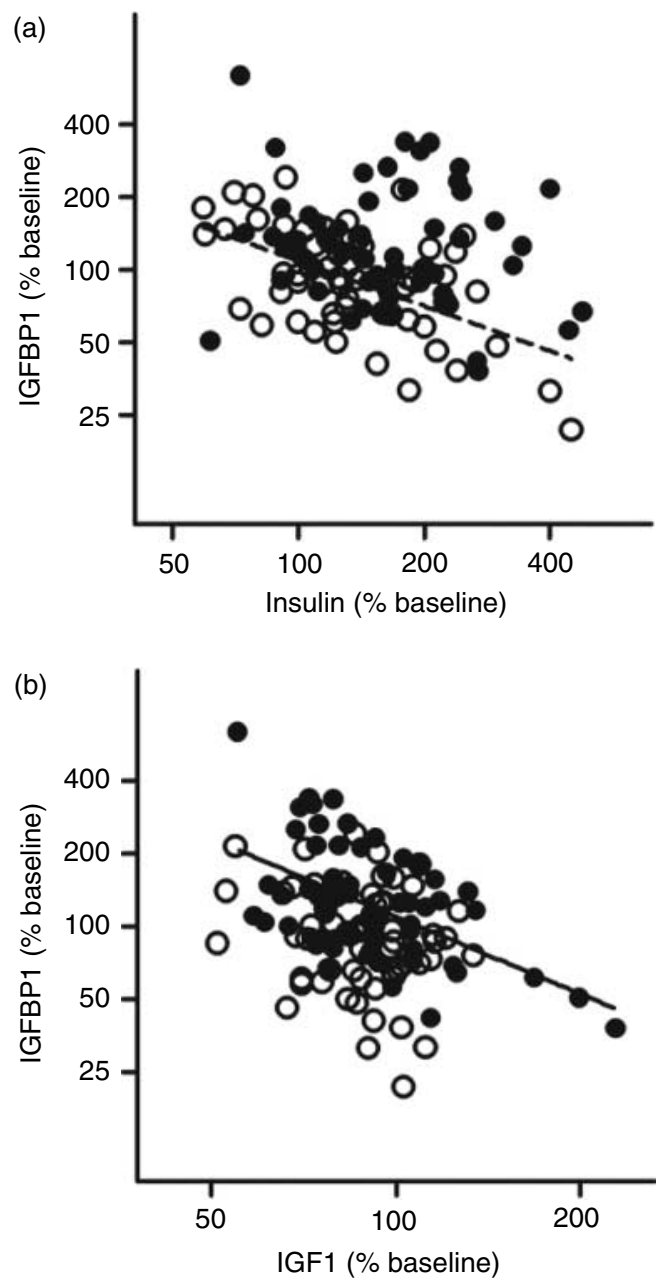

Figure 5 Relationship between the change in fasting IGFBP1 and the change in fasting insulin (a) or the change in IGF1 (b) in women developing diabetes at 8-year follow-up. The individuals developing diabetes $(n=60)$ are represented by the solid circles and unbroken regression lines, and are compared with their matched controls, which are represented by the open circles and broken regression lines. Correlation coefficients: (a) controls: $r=-0.54, P<0.001$; diabetes: $r=-0.16, P=0.212$; (b) controls: $r=-0.20, P=0.117$; diabetes: $r=-0.52, P<0.001$.

impaired IGFBP1 suppression after an oral glucose load. Women who developed diabetes were more likely to be obese than men. However, similar to men, IGFBP1 levels increased during the development of diabetes in women.

The design of the case-control study resulted in a majority of subjects with a FHD. The control group of men and women was matched for FHD, as well as gender and age. Although the women and men examined at the end of the study period were of similar age, the duration of follow-up was different. We have taken these limitations into account when examining gender differences in this population. Thus, our observations are in a Swedish population with high social and genetic predisposition to diabetes who developed abnormal glucose regulation within $8-10$ years of having had NGT.
IGFBP1 concentrations were higher in women compared to men of the same age, confirming observations in previous studies (19). The mechanism underlying the gender difference in IGFBP1 in humans is yet to be elucidated. In postmenopausal women, oral estrogens increase IGFBP1 concentrations (20, 21). This effect of estrogen appears to be independent of insulin $(22,23)$. Administration of testosterone to ageing men has no effect on circulating IGFBP1 levels (24). In this study, we have found that the circulating concentrations of insulin, the most important regulator of IGFBP1, were similar in women and men of the same age, suggesting that a difference in hepatic insulin sensitivity and/or the presence of other regulators of IGFBP1 is responsible for the gender difference.

An inverse relationship between fasting IGFBP1 and insulin was seen in the normal women, as previously observed in men from this population (6) and in other studies of healthy individuals $(25,26)$. In women developing diabetes, there was a similar inverse relationship between IGFBP1 and insulin at baseline. These women were relatively obese, and this preserved relationship has previously been reported in obesity $(27$, 28). Like the men, the inverse relationship was maintained in women after the development of diabetes, but the regression line shifted upwards, consistent with a decrease in hepatic insulin sensitivity or reduced hepatic insulin extraction (29). The regression line in women at follow-up was not different from the matched control group. In the men, however, the levels of IGFBP1 relative to the fasting insulin concentrations were above those of their age-matched controls at follow-up (6).

The observation that the women who developed diabetes had fasting IGFBP1 levels that were low relative to insulin concentrations is a novel one. While it is possible that this represents higher hepatic insulin sensitivity in the fasted state, we have recently shown that, in non-diabetic women and men with similar waist measurements, fasting IGFBP1 levels correlated with hepatic insulin sensitivity during a euglycaemic-hyperinsulinaemic clamp (30). This raises the question of a novel inhibitor of IGFBP1 production in the pre-diabetic state in women. We speculate that adipose tissue could be a source of that inhibitor.

Like the study in men, IGF1 levels in women who later developed diabetes were similar to controls, matched for age and FHD, and did not predict the development of abnormal glucose regulation. This lack of association with IGF1 was also seen in another prospective study in Sweden, in which low IGFBP1 predicted IGT and type 2 diabetes (31). However, we did observe an inverse relationship between the increase in IGFBP1 and the fall in IGF1 values after the development of diabetes. The cause of this phenomenon is unknown but was also seen in our previous study in men (6).

Obesity plays a very important role in the development of abnormal glucose regulation in middle-aged women $(7,8)$, and much of the epidemic of diabetes and 
the metabolic syndrome in women has been attributed to an increased prevalence of obesity $(32,33)$. A recent meta-analysis has identified waist-to-height ratio as the best discriminator of diabetes, hypertension and dyslipidaemia, over BMI (34). We have previously used $\mathrm{Wa}^{2} \mathrm{HtR}$ as measurement that takes into account the dependence of waist on height in men (6). We now find that this measurement is appropriate for women in the same population, although the reference range is lower than that of men. There were marked increases in $\mathrm{Wa}^{2} \mathrm{HtR}$ in all of the women during the time of the study regardless of glucose tolerance status, greater than those seen in the men over a longer follow-up period. This rapid development of central adiposity was not surprising since many of the women were experiencing menopause during the time of the study. Strategies that address the problem of weight gain are crucial in the prevention of diabetes. We observed that the women with impaired IGFBP1 suppression after an oral glucose load had the greatest increase in waist measurement. We would recommend that $\mathrm{Wa}^{2} \mathrm{HtR}$ might be used in screening women for the risk of developing diabetes. The finding of a low fasting IGFBP1 merely confirms this risk, but failure of IGFBP1 to suppress by more than $40 \%$ after an oral glucose load identifies a group with high risk of diabetes, which will be prone to an increase in abdominal fat. Relevance of these observations to other populations will be the focus of future studies.

\section{Supplementary data}

This is linked to the online version of the paper at http://dx.doi.org/10. 1530/EJE-10-0301.

\section{Declaration of interest}

The authors declare that there is no conflict of interest that could be perceived as prejudicing the impartiality of the research reported.

\section{Funding}

The study was supported by grants from the Swedish Research Council, Stockholm County Council, the Family Erling-Persson Foundation, Berth von Kantzows Foundation, the Swedish Council for Working Life and Social Research, the Swedish Diabetes Association, Novo Nordisk Scandinavia and GlaxoSmithKline.

\section{Acknowledgements}

The authors thank the Inga-Lena Wivall-Helleryd, Elvi Sandberg and Yvonne Strömberg for their technical assistance in performing IGFBP1, IGF1 and insulin assays, and the nurses, technicians and other staff members of the health care centres and laboratories who carried out the oral glucose tolerance tests and other assays.

\section{References}

1 Lee PDK, Giudice LC, Conover CA \& Powell DR. Insulin-like growth factor binding protein-1: recent findings and new directions. Proceedings of the Society for Experimental Biology and Medicine $1997216319-357$.
2 Heald AH, Cruickshank JK, Riste LK, Cade JE, Anderson S, Greenhalgh A, Sampayo J, Taylor W, Fraser W, White A \& Gibson JM. Close relation of fasting insulin-like growth factor binding protein-1 (IGFBP-1) with glucose tolerance and cardiovascular risk in two populations. Diabetologia 200144 333-339.

3 Kalme T, Seppala M, Qiao Q, Koistinen R, Nissinen A, Harrela M, Loukovaara M, Leinonen P \& Tuomilehto J. Sex hormone-binding globulin and insulin-like growth factor-binding protein-1 as indicators of metabolic syndrome, cardiovascular risk, and mortality in elderly men. Journal of Clinical Endocrinology and Metabolism 200590 1550-1556.

4 Rajpathak SN, McGinn AP, Strickler HD, Rohan TE, Pollak M, Cappola AR, Kuller L, Xue X, Newman AB, Strotmeyer ES, Psaty BM \& Kaplan RC. Insulin-like growth factor-(IGF)-axis, inflammation, and glucose intolerance among older adults. Growth Hormone and IGF Research 200818 166-173.

5 Laughlin GA, Barrett-Connor E, Criqui MH \& Kritz-Silverstein D. The prospective association of serum insulin-like growth factor I (IGF-I) and IGF-binding protein-1 levels with all cause and cardiovascular disease mortality in older adults: the Rancho Bernardo Study. Journal of Clinical Endocrinology and Metabolism 200489 114-120.

6 Lewitt MS, Hilding A, Ostenson CG, Efendic S, Brismar K \& Hall K. Insulin-like growth factor-binding protein-1 in the prediction and development of type 2 diabetes in middle-aged Swedish men. Diabetologia 200851 1135-1145.

7 Colditz GA, Willett WC, Rotnitzky A \& Manson JE. Weight gain as a risk factor for clinical diabetes mellitus in women. Annals of Internal Medicine 1995122 481-486.

8 Dotevall A, Johansson S, Wilhelmsen L \& Rosengren A. Increased levels of triglycerides, BMI and blood pressure and low physical activity increase the risk of diabetes in Swedish women. A prospective 18-year follow-up of the BEDA study. Diabetic Medicine 200421 615-622.

9 Legato MJ, Gelzer A, Goland R, Ebner SA, Rajan S, Villagra V \& Kosowski M. Gender-specific care of the patient with diabetes: review and recommendations. Gender Medicine 20063 131-158.

10 Regitz-Zagrosek V, Lehmkuhl E \& Weickert MO. Gender differences in the metabolic syndrome and their role for cardiovascular disease. Clinical Research in Cardiology 200695 136-147.

11 Mogul HR, Marshall M, Frey M, Burke HB, Wynn PS, Wilker S, Southern AL \& Gambert SR. Insulin-like growth factor-binding protein-1 as a marker for hyperinsulinemia in obese menopausal women. Journal of Clinical Endocrinology and Metabolism 199681 4492-4495.

12 Gibson JM, Westwood M, Young RJ \& White A. Reduced insulinlike growth factor binding protein-1 (IGFBP-1) levels correlate with increased cardiovascular risk in noninsulin dependent diabetes mellitus (NIDDM). Journal of Clinical Endocrinology and Metabolism 199681 860-863.

13 Eriksson AK, Ekbom A, Granath F, Hilding A, Efendic S \& Ostenson CG. Psychological distress and risk of pre-diabetes and type 2 diabetes in a prospective study of Swedish middle-aged men and women. Diabetic Medicine 200825 834-842.

14 World Health Organisation. Definition, Diagnosis and Classification of Diabetes Mellitus and its Complications: Report of a WHO Consultation. Part 1. Diagnosis and Classification of Diabetes Mellitus. Geneva: World Health Organization, 1999.

15 World Health Organisation. BMI Classification. Retrieved 25 July 2008, from http://www.who.int/bmi/index.jsp?intro Page=intro_3.html, 2008.

16 Póvoa G, Roovete A \& Hall K. Cross-reaction of serum somatomedin-binding protein in a radioimmunoassay developed for somatomedin-binding potein isolated from human amniotic fluid. Acta Endocrinologica 1984107 563-570.

17 Bang P, Eriksson U, Sara V, Wivall I-L \& Hall K. Comparison of acid ethanol extraction and acid gel filtration prior to IGF-I and IGF-II radioimmunoassays: improvement of determinations in acid ethanol extracts by the use of truncated IGF-I as radioligand. Acta Endocrinologica $1991 \mathbf{1 2 4} 620-629$. 
18 Herbert V, Lau KS, Gottlieb CW \& Bleicher SJ. Coated charcoal immunoassay of insulin. Journal of Clinical Endocrinology and Metabolism 196525 1375-1384.

19 Yeoh S-I \& Baxter RC. Metabolic regulation of the growth hormone independent insulin-like growth factor binding protein in human plasma. Acta Endocrinologica 1988119 465-473.

20 Cardim HJ, Lopes CM, Giannella-Neto D, da Fonseca AM \& Pinotti JA. The insulin-like growth factor-I system and hormone replacement therapy. Fertility and Sterility 200175 282-287.

21 Paassilta M, Karjalainen A, Kervinen K, Savolainen MJ, Heikkinen J, Backstrom AC \& Kesaniemi YA. Insulin-like growth factor binding protein-1 (IGFBP-1) and IGF-I during oral and transdermal estrogen replacement therapy: relation to lipoprotein(a) levels. Atherosclerosis 2000149 157-162.

22 Suikkari A-M, Tiitinen A, Stenman U-H, Seppälä M \& Laatikainen T. Oral contraceptives increase insulin-like growth factor binding protein-1 in women with polycytic ovarian disease. Fertility and Sterility $1991 \mathbf{5 5}$ 895-899.

23 Diel P, Walter A, Fritzemeier KH, Hegele-Hartung C \& Knauthe R. Identification of estrogen regulated genes in Fe33 rat hepatoma cells by differential display polymerase chain reaction and their hormonal regulation in rat liver and uterus. Journal of Steroid Biochemistry and Molecular Biology 199555 363-373.

24 Veldhuis JD, Frystyk J, Iranmanesh A \& Orskov H. Testosterone and estradiol regulate free insulin-like growth factor I (IGF-I), IGF binding protein 1 (IGFBP-1), and dimeric IGF-I/IGFBP-1 concentrations. Journal of Clinical Endocrinology and Metabolism 200590 2941-2947.

25 Hilding A, Brismar K, Degerblad M, Thorén M \& Hall K. Altered relation between circulating levels of insulin-like growth factorbinding protein-1 and insulin in growth hormone-deficient patients and insulin-dependent diabetic patients compared to that in healthy subjects. Journal of Clinical Endocrinology and Metabolism 199580 2646-2652.

26 Suikkari A-M, Koivisto VA, Koistinen R, Seppälä M \& Yki-Järvinen H. Dose-response characteristics for suppression of low molecular weight plasma insulin-like growth factor-binding protein by insulin. Journal of Clinical Endocrinology and Metabolism 198968 135-140.

27 Conover CA, Lee PDK, Kanaley JA, Clarkson JT \& Jenson MD. Insulin regulation of insulin-like growth factor binding protein-1 in obese and nonobese humans. Journal of Clinical Endocrinology and Metabolism 1992 74 1355-1360.

28 Weaver JU, Holly JMP, Kopelman PG, Noonan K, Giadom CG, White N, Virdee S \& Wass JAH. Decreased sex hormone binding globulin (SHBG) and insulin-like growth factor binding protein (IGFBP-1) in extreme obesity. Clinical Endocrinology 199033 $415-422$.

29 Kotronen A, Vehkavaara S, Seppala-Lindroos A, Bergholm R \& Yki-Jarvinen $\mathrm{H}$. Effect of liver fat on insulin clearance. American Journal of Physiology. Endocrinology and Metabolism 2007293 E1709-E1715.

30 Kotronen A, Lewitt M, Hall K, Brismar K \& Yki-Järvinen H. Insulin-like growth factor binding protein 1 as a novel specific marker of hepatic insulin sensitivity. Journal of Clinical Endocrinology and Metabolism 200893 4867-4872.

31 Petersson U, Östgren CJ, Brudin L, Brismar K \& Nilsson PM. Low levels of insulin-like growth factor-binding protein-1 (IGFBP-1) are prospectively associated with the incidence of type 2 diabetes and impaired glucose tolerance (IGT): the Söderåkra Cardiovascular Risk Factor Study. Diabetes \& Metabolism 200935 198-205.

32 Laakso M. Prevention of type 2 diabetes. Current Molecular Medicine 20055 365-374.

33 Steinbaum SR. The metabolic syndrome: an emerging health epidemic in women. Progress in Cardiovascular Diseases 200446 321-336.

34 Lee CM, Huxley RR, Wildman RP \& Woodward M. Indices of abdominal obesity are better discriminators of cardiovascular risk factors than BMI: a meta-analysis. Journal of Clinical Epidemiology $200861646-653$.

Received 10 May 2010

Accepted 27 May 2010 